\title{
Making the Most of College Revisited
}

Harvard University Press, Cambridge, MA, 2001, 242 pp.

ISBN 0-674-00478-7

\section{Reviewed by Christopher W. Tremblay}

Director of Admissions

Gannon University in Erie, PA.

Special thanks to Stanley Henderson, associate vice president for enrollment management at the University of Cincinnati, for recommending this text to me. Stan helped me make the most of my college experience and continues to serve as a mentor to me.

The function of orientation and transition programs is to help students make the most of college. Richard Light's Making the Most of College is a text that contains findings, insights and wisdom from college students about the role colleges play and should be playing in helping students maximize their college experience. On the most simplistic, metaphorical level, this book is to higher education administrators what transition books are for incoming new students: it offers perspective on the interconnectedness of college life. There are more than a dozen topics covered in the book that relate to orientation, ranging from study skills to diversity.

Chapter one is an introduction to the purpose behind the book. The philosophy of Light's writings comes down to two elements: (1) what the student does to benefit from 
college and (2) what the college does to support a student's college education. The combination of these two efforts should facilitate the best possible undergraduate experience. While the findings may seem basic upon first review, they are grounded on extensive conversations from hundreds of college students. Throughout the book are testimonials from some of the 1600 undergraduate students who were interviewed for the study. These short stories serve as examples that reinforce the student development and transition theories being taught in classrooms nationwide. The other eight chapters narrow in on the elements that have a significant impact on the undergraduate educational experience.

According to Light, the students who are most satisfied with college are those who make connections among their in-classroom and out-of-the-classroom experiences. Light continues to re-iterate the importance of good academic advising. At the end of this chapter, Light used the phrase "educational package" as a descriptor of the interconnectedness yet he did not refer to it later as expected. The overall message of this chapter is that there is a responsibility to help students make the connections that serve as the foundation of success.

Light honed in on the specific suggestions from students, ranging from time management to extracurricular participation, and reminded readers of the strong relationship between outside commitment and satisfaction in college. What is most surprising is when Light described the lack of a significant relationship between paid work and grades earned in courses. Furthermore, patterns of adjustment and living patterns along with symptoms of academic trouble were explored.

Light next described the learning process of students, focusing significantly on the dilemma that faces most faculty and academic deans: the writing levels and competencies of college students. Light pointed out, "writing plays a pivotal role in the academic lives of most students" (p. 55). His key points were that (1) the best learning takes place when writing is specific and substantial, and (2) writing improvement occurs when students enlist the help of peer reviewers. Light's research revealed that one of the best classroom organizational techniques is based on the use of current controversial topics to foster student engagement. He also offered advice to science and foreign language faculty for enhancing the classroom environment with changes in writing assignments.

Chapter five began with a statement "(g)ood advising may be the single most underestimated characteristic of a successful college experience" (p. 81). He believed the role of the advisor is pivotal for students because the advisor can help the student connect the relationship of their academic work to their personal lives. He reminded readers that advising should be customized to the student and advisors should encourage students to become involved.

In the next chapter he offered a prescription for how to become an unforgettable professor. An academic theme was continued, this time discussing the roles faculty play and their impact. Light emphasized that students gain confidence from working with faculty and they appreciate faculty who can link curriculum to student experiences. What stood out in this chapter was the example of the professor facilitating a "pick a number" exercise that demonstrated the behavior of large group settings like a lecture 
class. According to Light's research, an interdisciplinary approach to classroom instruction also is extremely effective.

Light also addressed the evolution of people on college campuses, referring to it as the "new student diversity" (p. 129) and saw it as the biggest change on campuses. Despite having poor diversity experiences in high schools, students must enter college with an open mind because the interactions they have are critical. He explained that even disagreements help in learning and maturation.

Using Chapter seven as a foundation, Light focused on the diversity of religion and the impact of diversity on college living in this chapter. Few college students grew up knowing of other religions other than the one they practiced as children. Light asserted that religious diversity is learned from peer social interactions rather than in the classroom. He also verbalized the challenge of integrating religion into academics. The latter part of the chapter described the importance of creating diverse living situations. Surprisingly, students choose to live with people who are different. Through these living situations, students gain self-awareness, helping them to become reflective practitioners.

Light then provided an outline of how to translate the information in the previous chapters into an action plan. Light used the language of the students in describing "campus culture builders," (p. 195), the people on campus who take the initiative, serve as the student advocates and who have an impact on their colleagues and the students. Part of being an effective administrator comes down to the basic principle: reminding students that college is a unique opportunity. Another noteworthy practice noted was scheduling classes in the residence halls before dinner because the conversation that continues during dinner can be powerful. The final message in this section was that administrators must get in the students way.

One of the final parts of the text is an overview of the research project and provides insight into the creation, evolution and implementation of this massive undertaking to collect student perspectives. Involving faculty and students along with having support from senior administrators were the keys to the success of the project. For educational professionals who wish to initiate assessments on their campuses, this section is most helpful.

The book is highly recommended and has great value in having new faculty and staff read it upon arriving on campus. The book represents the voice of the students placed in context with developmental and transition theories. Throughout the book Light points out that the findings can be applied to all types of educational institutions, not just Harvard. Overall, this publication serves as a prescription for improving the quality of life for students. 